Sharif University of Technology
Scientia Iranica
SCIENTIA

\title{
Experimental and theoretical investigations on spray characteristics of bio-ethanol blends using a direct injection system
}

\author{
A.R. Ghahremani ${ }^{a}$, M. Jafari ${ }^{\mathrm{b}}$, M. Ahari ${ }^{\mathrm{b}}$, M.H. Saidi $^{\mathrm{a}, *}$, A. Hajinezhad ${ }^{\mathrm{b}}$ \\ and A.A. Mozafari ${ }^{a}$ \\ a. Center of Excellence in Energy Conversion, School of Mechanical Engineering, Sharif University of Technology, Tehran, P.O. \\ Box 11155-9567 Iran. \\ b. Faculty of New Sciences and Technologies, University of Tehran, Tehran, Iran.
}

Received 26 June 2015; received in revised form 22 December 2015; accepted 4 April 2016

\section{KEYWORDS}

Bio-fuel;

Mixture formation;

Spray;

Visualization;

Schlieren.

\begin{abstract}
In the present work, the spray characteristics of bio-ethanol and its blends have been experimentally and theoretically investigated. To have a comprehensive study, the effects of ambient condition and injection pressure on the spray of different blends have been considered. Macroscopic and microscopic characteristics of spray such as tip penetration length, cone angle, projected area, volume, Sauter Mean Diameter (SMD), and Ohnesorge number are investigated precisely. Besides, air entrainment and atomization analyses have been carried out to improve mixture formation process. Using curve fitting and least squares method, theoretical correlations have been suggested in such a way to predict experimental results with the accuracy of $9.9 \%$. To have a good estimation of the calculated parameters, uncertainty analysis has been performed. The results demonstrate that enhancing the injection pressure or decreasing the ambient pressure improves the atomization characteristics of spray. Moreover, outcomes of this study indicate that spray tip penetration is enhanced by increasing the injection pressure or bio-ethanol percentage in the blend, while spray cone angle showing the opposite behavior.
\end{abstract}

(C) 2017 Sharif University of Technology. All rights reserved.

\section{Introduction}

Air pollution, caused by exhaust emission of vehicles, is currently one of the most important environmental issues. The international emission standards have become more and more restrictive during the recent years to control and promote the quality of automotive parts and vehicles. Consumption of bio-fuels, instead of common fuels, leads to the PM reduction and soot formation. Also, using Direct Injection (DI) engines

\footnotetext{
*. Corresponding author. Tel.: +982166164810; Fax: +982166035834

E-mail address: saman@sharif.edu (M.H. Saidi)
}

is another key way to reduce the fuel consumption and pollution simultaneously. Due to the limitation of fossil fuel resources and their environmental impacts, one of the key solutions is to consume biofuels in the DI engines. To realize the combustion behavior of bio-fuels, a comprehensive investigation on the spray formation of bio-fuels is necessary in this stage.

Wakuri et al. [1] took the momentum theory into consideration to investigate the spray penetration in a diesel engine. Their results indicated that the spray tip penetration is related to time, injection velocity, and the square of orifice diameter. The spray cone angle based on their report is proportional to the ambient 
density as well. With the aid of cold bomb method, Dent [2] studied the spray tip penetration. He represented a correlation that predicts spray tip penetration as well. His results demonstrated that the results of the mentioned formula had good agreement with those of experiments. Ayres et al. [3] applied the maximum entropy theory and developed a mathematical model to study the size and velocity of spray droplets. Their model is applicable to both jet and air blast atomizers. They showed that at the break-up process, the size and velocity of droplets are dependent on each other and increasing the size of droplets reduces the homogeneity of droplet size and velocity.

Hiroyasu and Kadota [4] employed liquid immersion sampling technique to measure the size of droplets of the fuel. Their results showed that SMD had a direct relationship with back pressure and indirect relationship with pump speed. Reitz and Bracco [5] applied two methods of visualization and using highspeed camera, they investigated the effects of ambient pressure, ambient gas, liquid density and pressure, and nozzle design on atomization mechanism. They developed a correlation for spray angle and startup of atomization and validated it by their own experimental results. Arai at al. [6] applied the electric resistance method and explored the break-up length of high-speed jet which was injected in the high pressure chamber. Their outcomes indicated that increasing the viscosity decreases the spray angle while SMD increases.

Kawahara and Nakayama [7] employed high-speed camera and long-distance microscope to explore the spray structure of Gasoline Direct Injection (GDI) engines near the swirl injector exit. They found that without using the swirl injector at the start of injection, the fuel behaves as a compact jet. In their work, length and thickness of liquid sheet are reported with the help of Ar-ion laser. Lee et al. [8] used the Particle Image Velocimetry (PIV) method and statistical entropy analysis to explore the characteristics of gasoline spray in a GDI system. The rate of homogeneity was reported as a result of entropy analysis. They found that entropy of spray is increased by the enhancement of ambient temperature from below to above of the fuel evaporation temperature. Employing Schlieren method, Gao et al. [9] investigated the spray formation of a number of gasoline bio-ethanol blends experimentally. Their work depicted that at the lower surrounding pressures, spray angle is directly related to the amount of bio-ethanol in the blend, while spray tip penetration is inversely related to bio-ethanol of blend as well. Fajardo and Sick [10] presented an extension of high speed PIV suitable for high luminous combustion condition of internal combustion engines. They reported the velocity domain at the top dead center in a DI engine with speed of 2000 RPM at the fired situation. Applying the Ultra-Violet (UV) PIV, they obtained flow fields and kinetic energy in a Spark Ignition Direct Injection (SIDI) engine. Matsumoto et al. [11] investigated spray properties of gasoline bio-ethanol blends employing Schlieren method and compared the consequences with those of Mie scattering and black lighting methods. The aforementioned experimental data were employed as an input of a Computational Fluid Dynamics (CFD) code (CONVERGE) to explore the spray behaviors such as tip penetration length, liquid, and vapor masses. Catapano et al. [12] explored physical and chemical characteristics of bio-ethanol and gasoline fuels in a visualized single cylinder DI engine. They varied engine load and speed to investigate their effects on the engine performance, emissions, spray parameters, and flame evolution. They reported that one of the best solutions to reduce emissions without losing efficiency is injecting bio-ethanol as a fuel with high pressure. Kourmatzis et al. [13] employing Phase Doppler Anemometry (PDA) and microscopic imaging investigated sprays of three bio-diesels and ethanol comparing momentum and droplet diameters. They also studied atomization characteristics, spray blockage, probability of short and long ligaments, deformed droplets, and unbroken liquid volumes as well. Padala et al. [14] employed Shadowgraph imaging and Mie scattering techniques; they investigated spray evolution of ethanol and compared those with gasoline's.

Their results revealed that evaporation of droplets which are close to the nozzle increases when injection is completed. Agarwal et al. [15] explored the influences of injection properties on the spray behavior and size distribution of Karanja bio-diesel and its blend with diesel fuel. Their results showed that increasing injection pressure enhances spray tip penetration and spray area and decreases amount of exhausted large substances considerably. They also exposed that adding $10 \%$ of Karanja to the diesel fuel reduces particulate emission significantly. Chen and Nishida [16] using Laser Absorption Scattering (LAS) technique investigated spray characteristics and combustion properties of three different blends of ethanol and gasoline. They indicated that due to the higher oxygen content of ethanol compared to gasoline, adding ethanol to the blend intensifies the combustion. They also showed that using blend of ethanol and gasoline in comparison with pure gasoline leads to better combustion stability.

Mohan et al. [17] studied spray properties and nozzle flow of methyl esters such as methyl oleate, methyl stearate, and methyl linoleate. They employed KIVA4 CFD codes and a combination of cavitation induced and KHRT models to simulate the spray characteristics and internal nozzle flow of fuels. Their results depicted that methyl stearate has minimum cavitation and maximum spray tip penetration length 


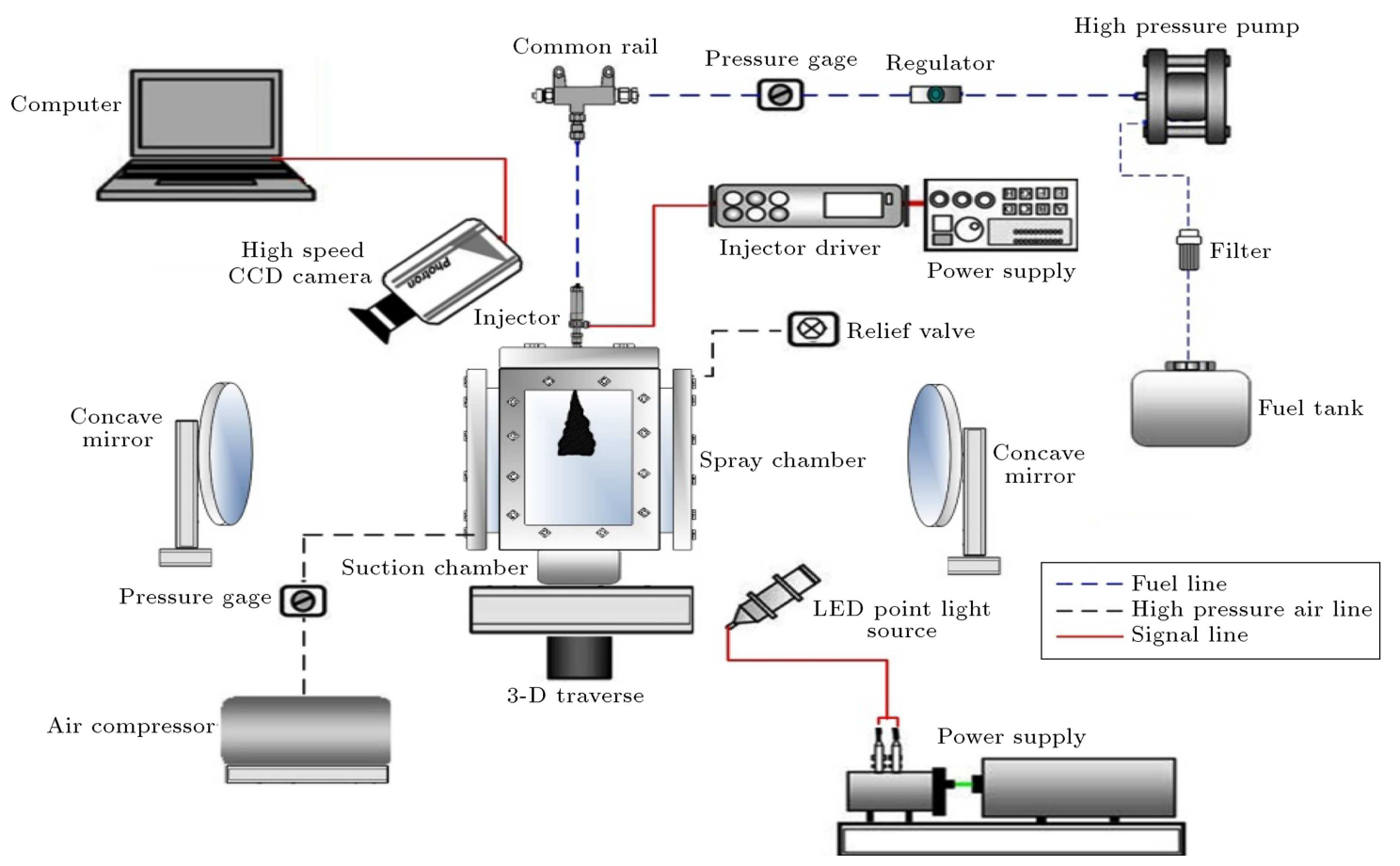

Figure 1. Schematic diagram of experimental setup.

compared with other's. Atomization modeling showed that atomization level of methyl linoleate is better than those of other methyl esters. Kharazmi et al. [18] experimentally and numerically studied the engine performance and exhaust emissions of a turbocharged engine using natural gas as a fuel. Their results illustrated that at engine speeds of higher than $1450 \mathrm{rpm}$, boost pressure remains constant and increasing the engine speed decreases $\mathrm{NO}$ emissions while $\mathrm{CO}_{2}$ has its minimum value for the case of mid speed ranges. Wang et al. [19] used the 3D nozzle structure to simulate the spray in FIRE v2010. Their results indicated that macroscopic and microscopic characteristics of the spray are mainly affected by cavitation properties. They also reported that the trends of SMD and spray tip penetration are controversial.

The main goal of the present study is to have a comprehensive investigation of spray atomization of bio-ethanol, gasoline, and their blends. To achieve this goal, the effects of injection and ambient conditions on the spray behavior of several blends are explored. Macroscopic characteristics of spray including tip penetration, shape, projected area, and cone angle are measured in a fabricated combustion chamber with the aid of high-speed imaging. Besides, theoretical correlations predicting experimental results have been extracted applying least squares method and curve fitting. Moreover, volume, equivalence ratio, Ohnesorge number, and Sauter Mean Diameter (SMD) have been calculated analytically, and uncertainty analysis has been performed to specify accuracy of the aforementioned parameters.

\section{Experimental apparatus and test procedures}

The experimental test rig and visualization technique, including injection system, Combustion Chamber (CC), and visualization equipment, are explained in detail in the following. Figure 1 illustrates the schematic diagram of the present test rig.

As illustrated in Figure 2(a), a vessel with three $70 * 130 \mathrm{~mm}$ optical windows is employed as a CC. The mentioned $\mathrm{CC}$ is designed and fabricated to pressurize till 15 bar. As Martin et al. [20] and Liu et el. [21] represented, surrounding pressure affects the spray properties significantly, while surrounding temperature does not have any important effect on them. Accordingly, in the present study, the ambient pressure is increased from surrounding pressure to the desired pressure, while the surrounding temperature and room temperature are the same. Before fabricating, the $\mathrm{CC}$ was modeled and analyzed in ANSYS. Figure 2(b) shows the ANSYS model set of CC. For safety purposes, one relief valve is embedded on the CC to prevent excess pressure above allowed limit. The ability of being operative with almost all of the visualization techniques was one of the priorities in designing the CC. Therefore, three optical windows are located around the $\mathrm{CC}$ in which two of them are in front of each other and the third window is perpendicular to those windows. The optical windows are made from BK7 due to its excellent optical performance. To regulate and control the pressure of $\mathrm{CC}$, a compressor, a Filter Regulator (FR), and three pressure gauges (one 


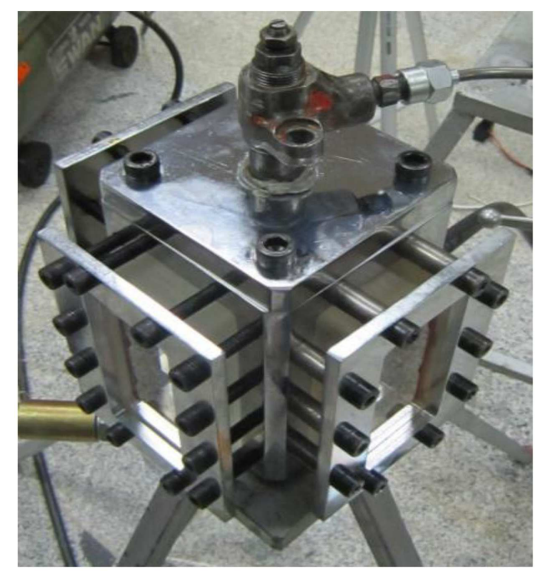

(a)

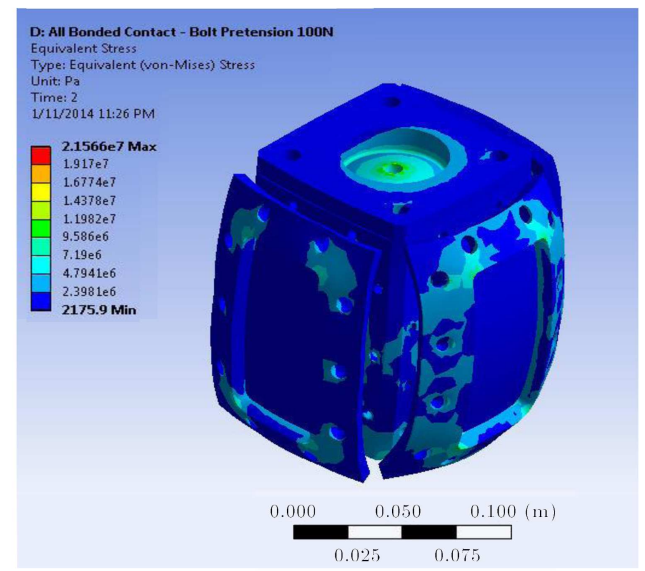

(b)

Figure 2. (a) Fabricated combustion chamber. (b) ANSYS modeling of combustion chamber.

after compressor, another one after FR, and the last one mounted to the $\mathrm{CC}$ ) are employed.

\subsection{Fuel properties and injection system}

Several research works have already paid attention to the spray properties of bio-fuels and their key roles on the mixture formation, combustion, and environmental issues [22-29]. In the present work, spray pattern and mixture formation of bio-ethanol and its blends with conventional gasoline have been examined, and influences of a number of parameters on spray characteristics of several blends have been performed. The blends of bio-ethanol and gasoline that are used in this research are designated as E100, E20, and E0, namely hundred percent of pure bio-ethanol, twenty percent of bio-ethanol, and bio-ethanol and pure gasoline fuel, respectively. Table 1 shows the physical properties of the aforementioned fuels. The main properties of these fuels which play key role on the spray behavior, such as viscosity, density, surface tension, and stoichiometric air fuel ratio, are presented in this table. To inject the spray to the $\mathrm{CC}$, the injection system contains high pressure pump, regulator, common rail, and injector. Fuel, which is pressurized at the high pressure pump to the desired pressure, goes through the regulator and common rail, and finally is injected in a single hole injector. The internal radius of the hole of the injector is $0.15 \mathrm{~mm}$. Furthermore, the injection pressure is monitored by means of a pressure transmitter and one 12-bit digital indicator.

\subsection{Visualization system and procedure}

The main component of visualization system is camera; hence, in the present study, a high-speed camera with the ability of imaging rate of up to $120,000 \mathrm{fps}$ is used. A Light-Emitting Diode (LED) with the power of $1 \mathrm{~W}$ as a light source and two optical mirrors with diameter of $90 \mathrm{~mm}$ are employed. Specifications of high-speed camera (MotionBLITZ Cube3) and other experimental imaging systems are reported in Table 2.

Table 1. Physical properties of the fuel tested.

\begin{tabular}{ccccc}
\hline Fuel & $\begin{array}{c}\text { Stoichiometric } \\
\text { air/fuel ratio }\end{array}$ & $\begin{array}{c}\text { Density } \\
\left(\mathbf{g} / \mathbf{c m}^{\mathbf{3}}\right)\end{array}$ & $\begin{array}{c}\text { Kinematic viscosity } \\
\left(\mathbf{m m}^{\mathbf{2}} \mathbf{s}\right)\end{array}$ & $\begin{array}{c}\text { Surface tension } \\
(\mathbf{m N} / \mathbf{m})\end{array}$ \\
\hline E0 & 15.1 & 0.749 & 0.64 & 18.680 \\
E20 & 14.54 & 0.757 & 0.77 & 18.790 \\
E100 & 9 & 0.788 & 1.58 & 19.830 \\
\hline
\end{tabular}

Table 2. Specifications of experimental visualization system.

\begin{tabular}{|c|c|c|}
\hline Camera (MotionBLITZ Cube3) & $\begin{array}{l}\text { Resolution } \\
\text { Speed } \\
\text { Pixel size }\end{array}$ & $\begin{array}{c}\text { Up to } 512^{*} 512 \text { pixel } \\
\text { Up to } 120,000 \mathrm{fps} \\
16^{*} 16 \mu \mathrm{m}\end{array}$ \\
\hline Light source (LED) & Power & $1 \mathrm{~W}$ \\
\hline Mirrors & $\begin{array}{c}\text { Diameter } \\
\text { Surface curve } \\
\text { Focal distance }\end{array}$ & $\begin{array}{l}90 \mathrm{~mm} \\
\text { Parabolic } \\
67 \mathrm{~cm}\end{array}$ \\
\hline
\end{tabular}


Visualization technique which is applied in this work is Schlieren method. Fuel goes from storage desired pressure, and then is delivered to the common rail through the fuel rails. After that, fuel will be injected to the $\mathrm{CC}$ via injector. Simultaneously, light goes across the $\mathrm{CC}$ with the help of mirrors and reaches the camera sensor. Images are recorded in the computer and post-processing should be accomplished to investigate the spray characteristics and mixture formation. A user-friendly software, namely "Image Analyzer Pro.", is developed in our group to analyze the recorded image. User just get the images as an input of the software, then software analyzes the images and reports atomization behavior, mixture formation, microscopic and macroscopic characteristics of spray. Based on the spray propagation speed, frequency of imaging is adjusted to the $6000 \mathrm{fps}$.

Variables are normalized employing the following time and length scales:

$$
\begin{aligned}
& S^{+}=\frac{d_{o} \tan \left(\frac{\theta}{2}\right)}{\sqrt{\frac{\rho_{f}}{\rho_{a}}}}, \\
& t^{+}=\frac{d_{o} \tan \left(\frac{\theta}{2}\right)}{u_{o} \sqrt{\frac{\rho_{f}}{\rho_{a}}}},
\end{aligned}
$$

where $u_{o}=\sqrt{\frac{2\left(P_{\mathrm{inj}}-P_{a}\right)}{\rho_{f}}}$ is fuel velocity at the orifice exit [30]. Based on this, the non-dimensional numbers are obtained as:

$$
\begin{aligned}
& S^{*}=\frac{S}{S^{+}}, \quad t^{*}=\frac{t}{t^{+}}, \\
& A^{*}=\frac{A}{\left(S^{+}\right)^{2}}, \quad \text { and } \quad V^{*}=\frac{V}{\left(S^{+}\right)^{3}} .
\end{aligned}
$$

\section{Experimental results}

Tip penetration length and cone angle, which are frequently reported and compared in the literature, tank to high pressure pump and is pressurized to the

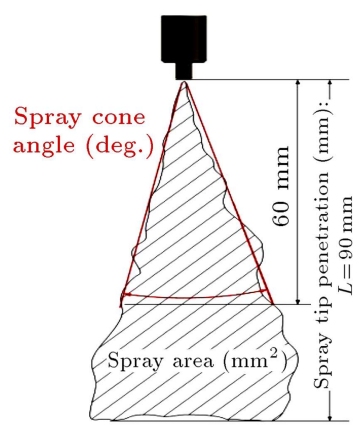

(a)

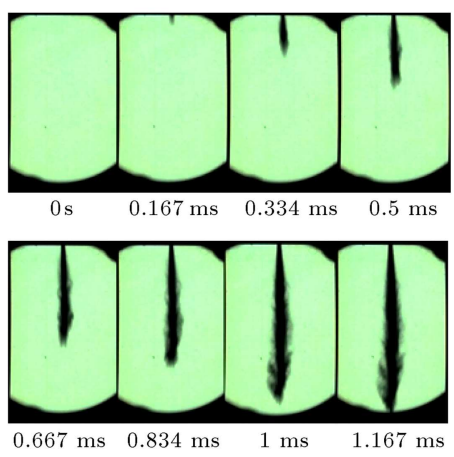

(b)
Figure 3. (a) Definition of spray macroscopic characteristics. (b) Visualization of spray at different time.

are defined in Figure 3(a). As it is obvious in this figure, tip penetration length is defined as a distance between the injector tip and the farthest part of the spray. Likewise, angle formed between injector hole and external perimeter of spray at distance of $60 \mathrm{~mm}$ (about 200 times of orifice diameter) away from exit hole is chosen as a cone angle. Figure 3(b) represents the spray evolution process with time in the chamber for a typical condition of spray.

\subsection{Spray tip penetration length}

Variation of tip penetration for different blends of bioethanol and gasoline in different ambient and injection conditions are analyzed and revealed in Figure 4. Figure 4(a) and (b) display non-dimensional spray tip penetration of the forenamed fuels versus nondimensional time for different injection pressures. Each figure contains some curves for two ambient conditions and three blends. Spray tip penetration trend is similar for all tests. Increasing the ambient pressure decreases penetration length as a result of enhancing the ambient density, which plays a role as a wall to prevent spray development. Furthermore, results illustrate that decreasing bio-ethanol percentage in the fuel leads to the lower tip penetration because of reducing the density and viscosity. As expected, pen-

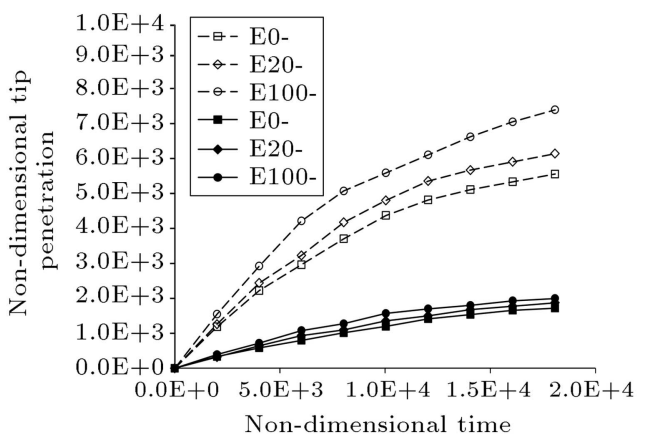

(a)

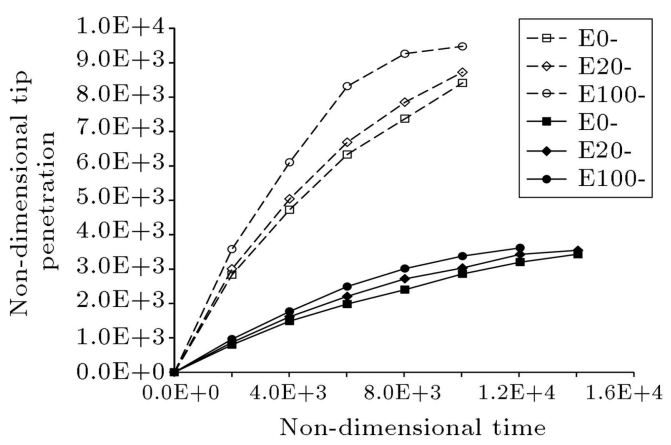

(b)

Figure 4. Non-dimensional spray tip penetration length versus non-dimensional time for different conditions: (a) $P_{\text {inj }}=100$ bar, and (b) $P_{\text {inj }}=200$ bar. 


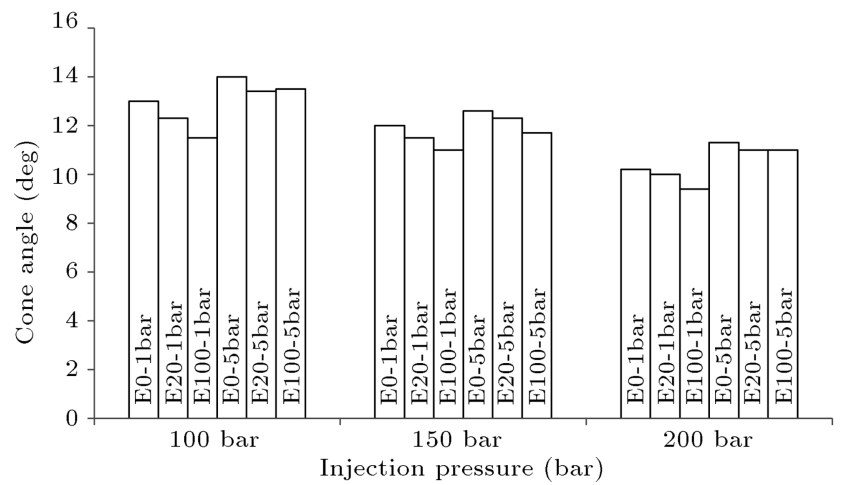

Figure 5. Average spray cone angle for different injection pressures and mixture conditions.

etration length is increased by enhancing the injection pressure.

In this work, due to the physics of spray, an equation with several coefficients for predicting variation of spray tip penetration versus time has been extracted. By applying curve fitting and least squares method, the aforementioned coefficients have been computed as follows:

$$
\begin{aligned}
S= & C_{1}\left(1-e^{-C_{2} t}\right), \\
C_{1}= & 0.0006 \rho_{f}^{-0.4354} \rho_{a}^{-0.0027} v_{f}^{0.1033} \sigma_{f}^{-1.0107} \\
& \left(P_{\mathrm{inj}}-P_{a}\right)^{0.3316}, \\
C_{2}= & 0.7441 \rho_{f}^{-0.8508} \rho_{a}^{-0.3114} v_{f}^{-0.0521} \sigma_{f}^{2.2471} \\
& \left(P_{\mathrm{inj}}-P_{a}\right)^{0.6239} .
\end{aligned}
$$

Difference between computed tip penetration based on the abovementioned equation and the experimental results is less than $9.9 \%$ which shows reliability and validity of using that correlation.

\subsection{Spray cone angle}

Spray cone angle is one of the most important parameters and has a great effect on mixture formation.

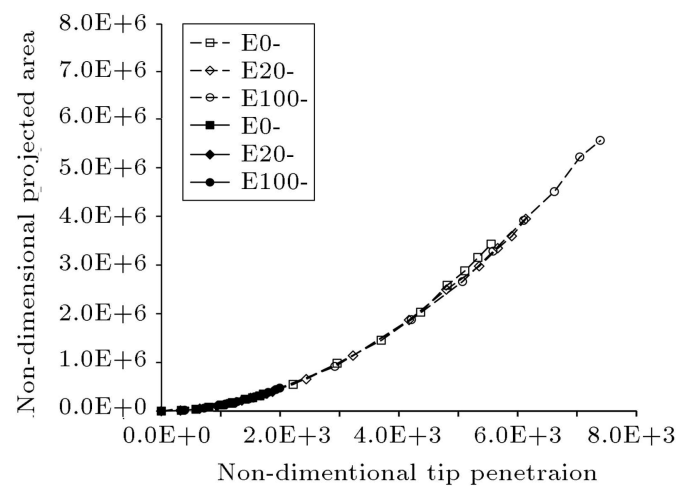

(a)
Figure 5 reveals average cone angle for various ambient conditions, injection pressures, and blends. Spray cone angle deviation for different conditions is not very tangible and for all cases is about 10-14 degrees. Nevertheless, cone angle increases by enhancing ambient pressure or decreasing injection pressure. Actually, growing ambient pressure leads to greater ambient density and preventing spray to go forward, so spray is forced to expand radially. Furthermore, adding bioethanol to the blend leads to reducing cone angle.

\subsection{Spray area}

The non-dimensional spray projected area versus nondimensional spray tip penetration length for different injection pressures and mixtures is displayed in Figure 6 . It is clear that increasing both cone angle and penetration length tend to increase projected area, although the spray cone angle and penetration length do not show similar behavior. In this respect, there is no significant difference between spray areas of different blends at different ambient pressures. Figure 6 also shows that increasing injection pressure increases spray projected area due to the increase of the tip penetration length.

Applying curve fitting and least squares method lead to another correlation which predicts variation of spray area with tip penetration length, as suggested in Eq. (4). The predicting results of this equation have diversity of lower than $7.8 \%$ compared with those of empirical relations:

$$
\begin{aligned}
A= & C_{1} s^{2}+C_{2} s, \\
C_{1}= & 66.9446 \rho_{f}^{-0.1964} \rho_{a}^{0.0558} v_{f}^{-0.0528} \sigma_{f}^{0.2419} \\
& \left(P_{\mathrm{inj}}-P_{a}\right)^{-0.3062}, \\
C_{2}= & 2.4395 \times 10^{-10} \rho_{f}^{0.0132} \rho_{a}^{-0.2207} v_{f}^{0.5999} \sigma_{f}^{-4.1327} \\
& \left(P_{\mathrm{inj}}-P_{a}\right)^{0.3177} .
\end{aligned}
$$

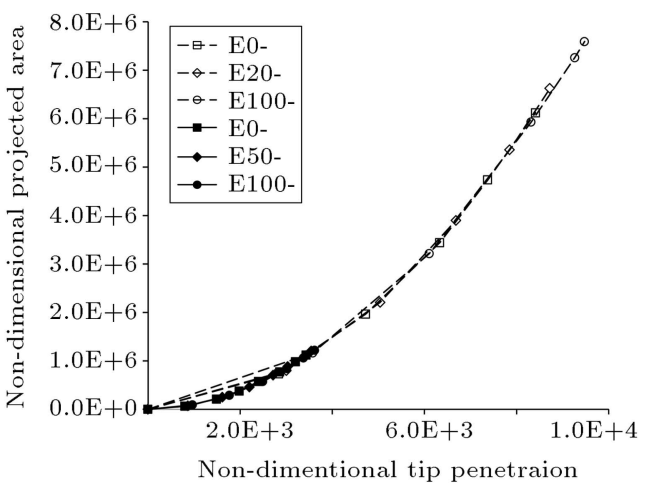

(b)

Figure 6. Non-dimensional spray projected area versus non-dimensional tip penetration length for different injection pressures and mixture conditions: (a) $P_{\text {inj }}=100$ bar, and (b) $P_{\text {inj }}=200$ bar. 


\section{Theoretical and empirical results}

The most important macroscopic and microscopic characteristics of spray formation, such as spray volume, equivalence ratio, Ohnesorge number, and Sauter Mean Diameter (SMD), are discussed in detail in the following. The objective is to explore the mixture formation and spray atomization.

\subsection{Uncertainty analysis}

To have a good estimation of the accuracy of computed parameters, uncertainty analysis should be performed. The error analysis has been performed by general method which was used by Ejim et al. [31] and Mohammadi et al. [32]. General form of uncertainty analysis is as follows:

$$
\frac{U_{Y}}{Y}=\sqrt{\left(\sum_{i=1}^{n}\left(\frac{1}{Y} \frac{\partial Y}{\partial X_{i}} U_{X_{i}}\right)^{2}\right)}
$$

where $U_{Y}$ and $U_{X_{i}}$ are uncertainties of parameters $Y$ and $X_{i}$, respectively; and $n$ denotes the number of dependent parameters.

\subsection{Spray volume}

Spray volume could be obtained by mathematical correlation. Delacourt et al. [33] suggested an estimated correlation for spray volume. Spray volume based on this equation is related to spray tip and cone angle and is reported as follows:

$$
V(t)=\frac{\pi}{3} S^{3}(t) \tan ^{2}\left(\frac{\theta(t)}{2}\right) \frac{1+2 \tan \left(\frac{\theta(t)}{2}\right)}{\left(1+\tan \left(\frac{\theta(t)}{2}\right)\right)^{3}},
$$

where $S(t)$ and $\theta(t)$ are spray tip penetration and cone angle for specified time, $t$, respectively.

Since uncertainties of measuring tip penetration length and cone angle are $0.0002 \mathrm{~m}$ and $0.006 \mathrm{rad}$, respectively; maximum error in calculating volume is $7.5 \%$ according to Eqs. (5) and (6).

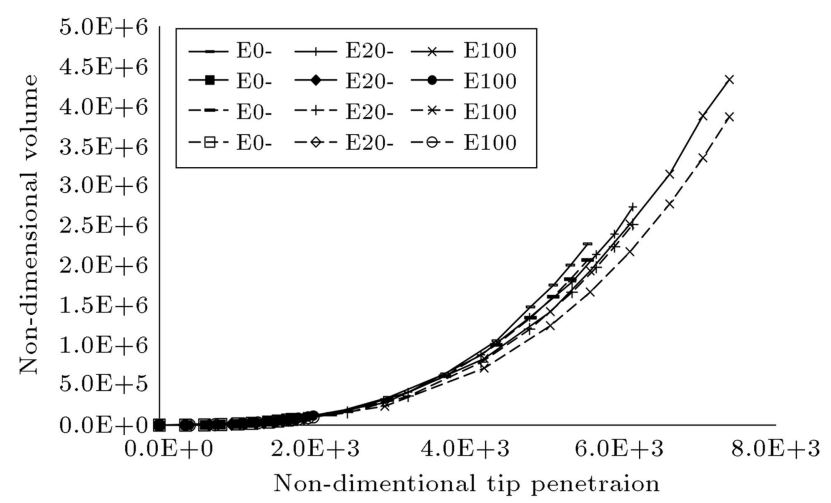

(a)
Assuming a geometric cone for the spray is another way to compute the volume of injected spray. Recalling the mathematical relation between the volume, projected area, and radius of rectangle of the cone, namely $V=\frac{\pi}{3} r A$, we may sketch the volume versus tip penetration based on mathematical efforts.

Variation of non-dimensional spray volume versus non-dimensional spray tip penetration for a number of ambient conditions, injection pressures, and fuel blends, based on the above correlations, is depicted in Figure 7. As it can be seen in Figure 7(a) and (b), spray volume trend is similar to that of spray projected area shown in Figure 6. As shown in Figure 7, there is good agreement between the two sets of curves, which are based on the volumes computed with the two abovementioned relations, and the trends for both are increasing; adding bio-ethanol to the blend reduces spray volume for both of curves. Increasing the injection pressure increases spray volume as a result of increased tip penetration length as well.

\subsection{Equivalence ratio}

Wang et al. [30] studied air entrainment applying turbulent jet theory based on the work of other scholars such as Naber and Siebers [34], Desantes et al. [35], and Zhang et al. [36]. The following equation describes equivalence ratio in radial and axial directions [30]:

$$
\phi(x, r)=2.55 \bar{\phi}(x) e^{-\alpha\left(\frac{r}{R}\right)^{2}},
$$

where $R=x \tan \left(\frac{\theta}{2}\right), \alpha$ is the shape factor of the Gaussian distribution, and $\bar{\phi}(x)$ is the average cross sectional equivalence ratio at any $x$ location which can be computed using the following equation:

$$
\bar{\phi}(x)=\frac{2(\mathrm{AF})_{\mathrm{st}}}{\sqrt{1+16\left(\frac{x}{x^{*}}\right)^{2}}-1},
$$

where $(\mathrm{AF})_{\text {st }}$ is the stoichiometric air fuel ratio and $x^{*}$ is the characteristic length scale which is defined as:

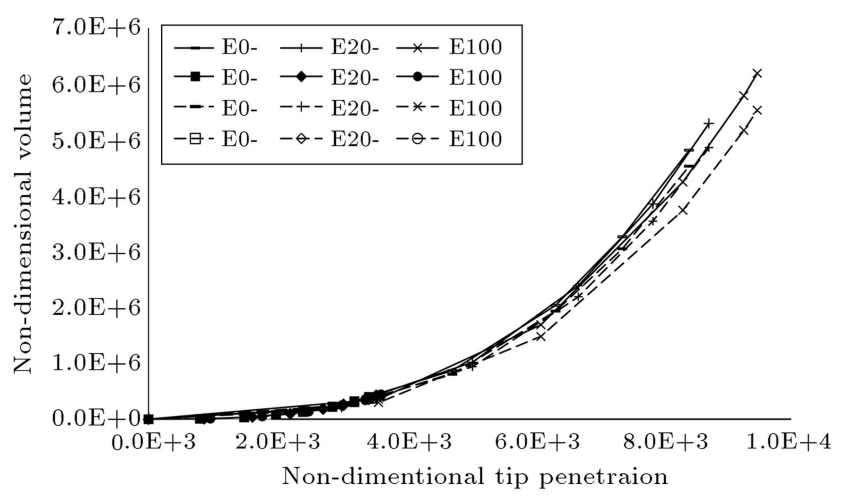

(b)

Figure 7. Spray volume versus spray tip penetration length for different conditions based on two correlations: (a) $P_{\text {inj }}=100$ bar, and (b) $P_{\text {inj }}=200$ bar. 


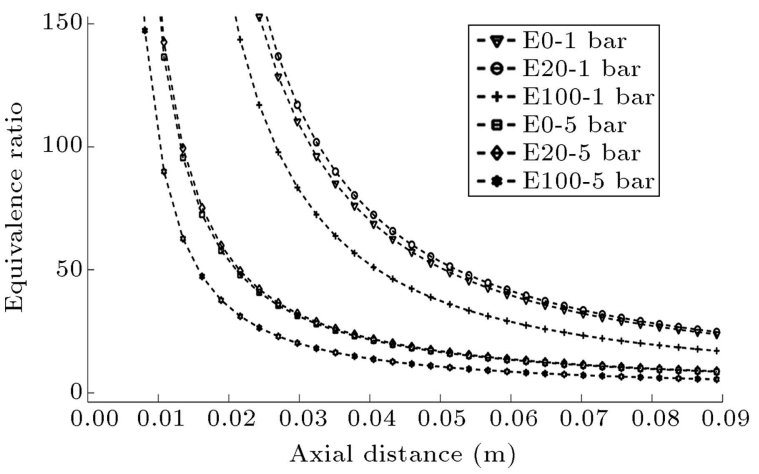

(a)

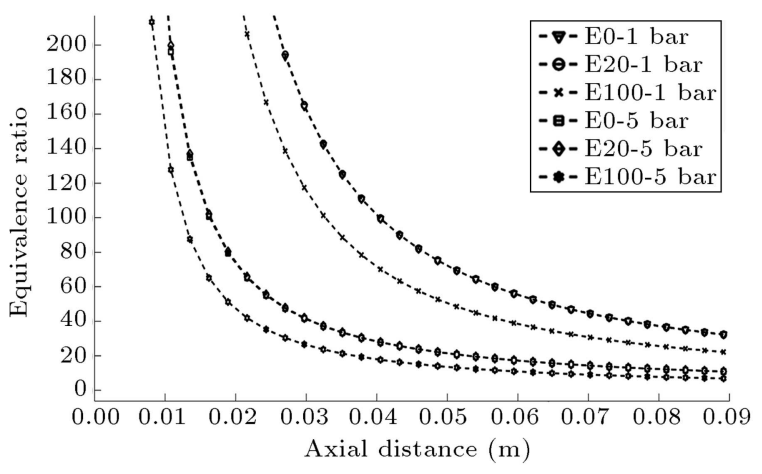

(b)

Figure 8. Equivalence ratio along axial direction $(r=0)$ for different injection pressures: (a) $P_{\text {inj }}=100$ bar, and (b) $P_{\text {inj }}=200$ bar.

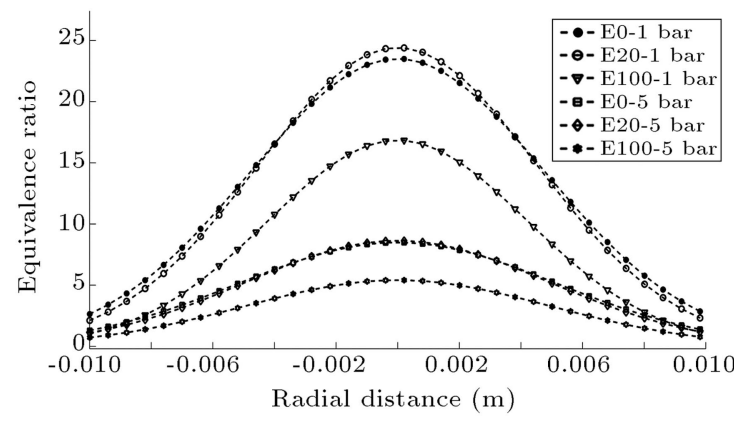

(a)

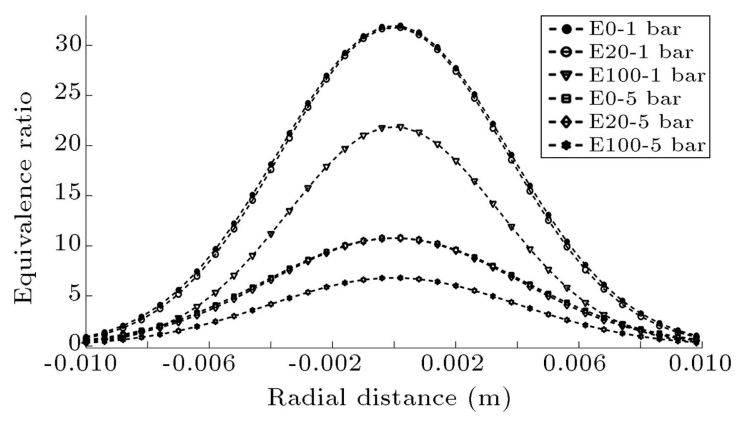

(b)

Figure 9. Equivalence ratio through radial direction $(x=90 \mathrm{~mm})$ for various injection pressures: $(\mathrm{a}) P_{\mathrm{inj}}=100 \mathrm{bar}$, and (b) $P_{\text {inj }}=200$ bar.

$$
x^{*}=\frac{\sqrt{\rho_{f} c_{a}} d_{o}}{0.75 \sqrt{\rho_{a}} \tan \left(\frac{\theta}{2}\right)},
$$

where $c_{a}$ is the orifice area contraction coefficient, $d_{o}$ is the orifice diameter, and $\rho_{f}$ and $\rho_{a}$ are fuel and ambient densities, respectively.

Equivalence ratio mainly depends on the stoichiometric air fuel ratio, so the equivalence ratio of gasoline is greater than that of other blends. On the other hand, increasing bio-ethanol to blend reduces equivalence ratio and required air entrance too. Figures 8 and 9 demonstrate equivalence ratio for different blends and various ambient and injection conditions along the axial and radial directions.

Equivalence ratio profile along the $x$-direction and nozzle hole (at $r=0$ ) from injector tip to $x=90 \mathrm{~mm}$ is shown in Figure 8. Figure 8(a) and (b) are for injection pressures of 100 and 200 bars, respectively. The abovementioned figure shows that almost increasing bio-ethanol ratio in the blend or enhancing the ambient pressure both decline the equivalence ratio.

Figure 9 represents variation of equivalence ratio along r-direction at the end of spray $(x=90 \mathrm{~mm})$ for different blends, ambient, and injection conditions. As it is obvious in this figure, equivalence ratio reduces by heightening the ambient pressure due to boosting ambient density. Also, Figure 9 illustrates that the higher ambient pressure causes the wider equivalence profile.

\subsection{Ohnesorge number}

The Ohnesorge number is one of the most applicable dimensionless numbers relating to viscous, inertia, and surface tension forces. Ohnesorge number is defined by the following equation:

$$
\mathrm{oh}=\frac{\mu}{\sqrt{\rho \sigma L}}
$$

where $\mu, \rho, \sigma$, and $L$ are viscosity, density, surface tension, and characteristic length scale, respectively.

Maximum measuring errors of density, surface tension, kinematic viscosity, and characteristic length scale are $1 \%, 0.06 \%, 1 \%$, and $8.2 \%$, respectively. Employing Eq. (5) clarifies that the maximum uncertainty of calculating Ohnesorge number is $4.3 \%$.

Wu et al. [37] reported some stages of atomization based on the results of Reitz [38] to quantify the spray atomization. Figure 10 shows Ohnesorge number versus Reynolds number separating poor and strong atomization zones. With the aid of this figure, one can predict the atomization properties of injected sprays. As indicated in Figure 10, increasing injection 


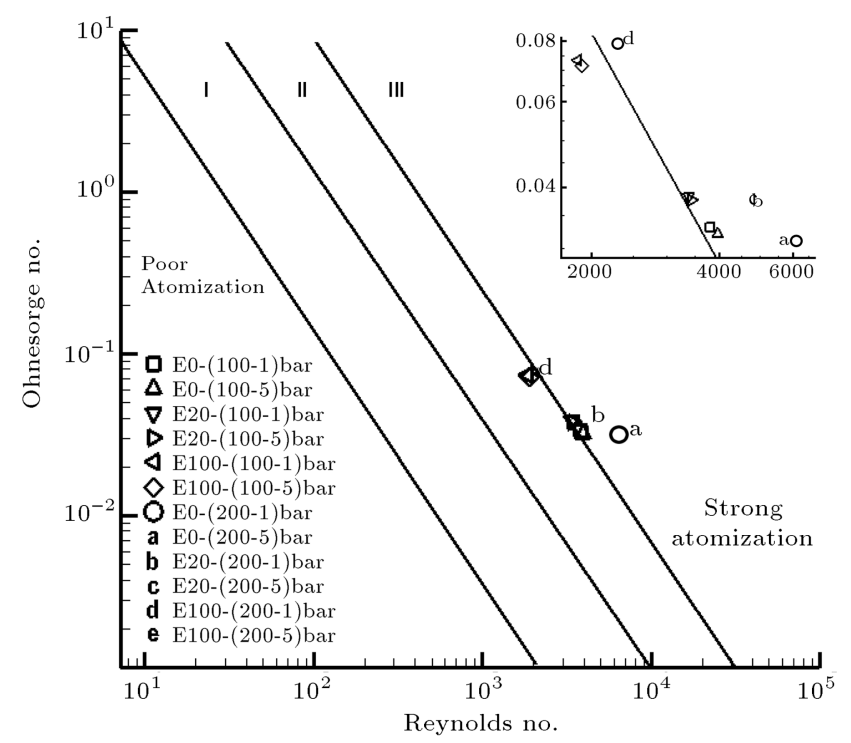

Figure 10. Ohnesorge number versus Reynolds number showing different atomization zones.

pressure increases Reynolds number and leads to the promoted atomization level which is desired. Adding bio-ethanol in the blend decreases Reynolds number, while enhances Ohnesorge number due to increasing viscosity of blend and keeps atomization level in the strong atomization zone.

\subsection{Sauter Mean Diameter (SMD)}

SMD is equal to the diameter of a sphere which has the same volume to area ratio of a non-spherical particle. Viscosity, surface tension, and density of fuel and ambient are the key parameters affecting the SMD of injected spray. Knowing SMD helps researchers to have a wide look on the atomization characteristics of injected sprays. Ejim et al. [31] reported a correlation for SMD as follows:

$$
\mathrm{SMD}=6156 \rho_{a}^{0.06} \rho_{f}^{0.737} v_{f}^{0.385} \sigma_{f}^{0.737}\left(P_{\mathrm{inj}}-P_{a}\right)^{-0.54},
$$

where $v_{f}$ and $\sigma_{f}$ are fuel viscosity and surface tension, and $P_{\text {inj }}$ and $P_{a}$ are symbols of injection and ambient pressures, respectively.

According to the accuracy of measuring pressure, which is 0.1 bar, and Eq. (5), maximum uncertainty for calculating SMD is $8.2 \%$.

Since the abovementioned equation is not precise, having an approximation for SMD to compare atomization properties of blended fuels is considered here. Figure 11 displays SMD of tested blends at different injection and ambient conditions. According to Eq. (11), SMD is proportional to density, viscosity, surface tension, and pressure difference. As seen in Figure 11, enhancing injection pressure or percentage of gasoline in the blend and decreasing the ambient pressure decline SMD, and consequently improves the atomization behavior of injected sprays.

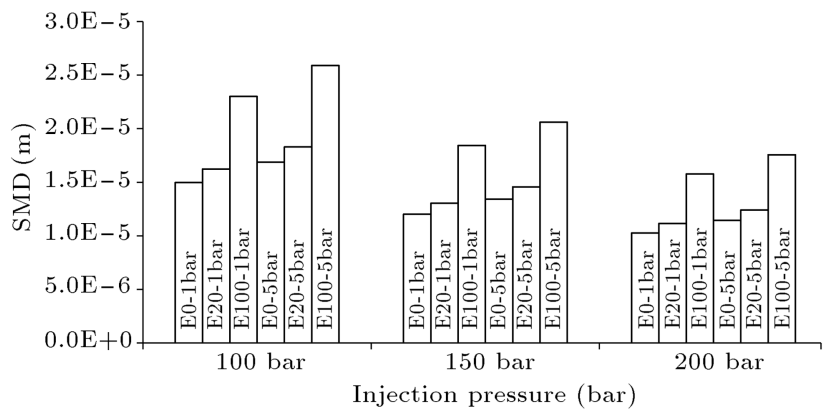

Figure 11. Sauter Mean Diameter (SMD) versus injection pressure at different fuel mixtures and corresponding pressures.

\section{Conclusion}

Spray behaviors of some blends of bio-ethanol and gasoline under various ambient and injection states have been studied experimentally and theoretically in this research. Ambient pressures of 1 and 5 bars, and injection pressures of 100 and 200 bars are varied to investigate their influences on spray of blends. Three blends from E0 to E100 were chosen as testing fuels. Macroscopic and microscopic behaviors of sprays such as tip penetration length, cone angle, projected area, volume, Sauter Mean Diameter (SMD), and Ohnesorge number under abovementioned conditions have been examined. In addition, air entrainment and atomization analysis have been explored with the goal of a better recognition of mixture formation process. Key results of the present research could be summarized as:

- Increasing the ambient pressure decreases penetration length, although enhancing bio-ethanol percentage in the fuel and injection pressure leads to higher tip penetration;

- Cone angle increases by enhancing ambient pressure, reducing injection pressure, or decreasing bioethanol of the blend;

- Spray projected area grows by increasing injection pressure, while ambient pressure and gasoline proportion of the blend have no important effect on it;

- Raising bio-ethanol of the blend reduces equivalence ratio and required air entrance due to a lower stoichiometric air fuel ratio of bio-ethanol compared with gasoline;

- Higher ambient pressure leads to wider equivalence profile;

- Rising injection pressure amplifies Reynolds number, and therefore improves atomization grade of spray;

- To promote atomization and decrease SMD, injection pressure should be increased, or ambient pressure must be reduced; 
- Due to increase of viscosity of blend, however, adding bio-ethanol to the blend reduces Reynolds number and enhances SMD; it increases the Ohnesorge number and keeps the atomization level of the spray in the strong atomization zone.

\section{Acknowledgement}

This work has been supported by INSF. Authors of the present research want to express their gratitude to Dr. Zabetian and Dr. Assadian for their kind help in this work. Also, they should say thanks to authorities of Islamic Azad University of Science and Research of Tehran, Dr. Abbasspour, and Dr. Javid for their technical support.

\section{Nomenclature}

$\begin{array}{ll}A & \text { Spray area } \\ (\mathrm{AF})_{s t} & \text { Stoichiometric air fuel ratio } \\ C_{a} & \text { Orifice area contraction coefficient } \\ d & \text { Diameter } \\ f p s & \text { Frame per second } \\ \mathrm{Oh} & \text { Ohnesorge number } \\ P & \text { Pressure } \\ \operatorname{Re} & \text { Reynolds number } \\ S & \text { Spray tip penetration } \\ t & \text { Time } \\ V & \text { Spray volume } \\ x^{*} & \text { Characteristic length scale }\end{array}$

\section{Greek symbols}

$\begin{array}{ll}\sigma & \text { Surface tension } \\ v & \text { Kinematic viscosity } \\ \theta & \text { Spray cone angle } \\ \alpha & \text { Shape factor of Gaussian distribution } \\ \phi & \text { Equivalence ratio } \\ \rho & \text { Density }\end{array}$

\section{Subscripts}

$\begin{array}{ll}a & \text { Ambient } \\ f & \text { Fuel } \\ \text { inj } & \text { Injection } \\ o & \text { Orifice }\end{array}$

\section{References}

1. Wakuri, Y., Fujii, M., Amitani, T. and Tsuneya, R. "Studies on the penetration of fuel spray in a diesel engine", Bulletin of JSME, 3(9), pp. 123-130 (1960).
2. Dent, J.C. "A basis for the comparison of various experimental methods for studying spray penetration", In SAE Technical Paper (1971).

3. Ayres, D., Caldas, M., Semiao, V. and da Graca Carvalho, M. "Prediction of the droplet size and velocity joint distribution for sprays", Fuel, 80(3), pp. 383-394 (2001).

4. Hiroyasu, H. and Kadota, T., Fuel Droplet Size Distribution in Diesel Combustion Chamber, in, SAE Technical Paper (1974).

5. Reitz, R.D. and Bracco, F.B. "On the dependence of spray angle and other spray parameters on nozzle design and operating conditions", In SAE Technical Paper (1979).

6. Arai, M., Tabata, M., Hiroyasu, H. and Shimizu, M. "Disintegrating process and spray characterization of fuel jet injected by a diesel nozzle", in, SAE Technical Paper (1984).

7. Kawahara, M.S.N. and Nakayama, E.T.T. "Microscopic observation of primary spray structure of highpressure swirl injector for gasoline direct injection engine", In The 9th Int. Conf. on Liquid Atomization and Spray Systems (2003).

8. Lee, K., Lee, C. and Lee, C. "An experimental study on the spray behavior and fuel distribution of GDI injectors using the entropy analysis and PIV method", Fuel, 83(7), pp. 971-980 (2004).

9. Gao, J., Jiang, D. and Huang, Z. "Spray properties of alternative fuels: A comparative analysis of ethanolgasoline blends and gasoline", Fuel, 86(10), pp. 16451650 (2007).

10. Fajardo, C. and Sick, V. "Development of a highspeed UV particle image velocimetry technique and application for measurements in internal combustion engines", Experiments in Fluids, 46(1), pp. 43-53 (2009).

11. Matsumoto, A., Moore, W.R., Lai, M.-C., Zheng, Y., Foster, M., Xie, X.-B., Yen, D., Confer, K. and Hopkins, E. "Spray characterization of ethanol gasoline blends and comparison to a CFD model for a gasoline direct injector", SAE Technical Paper, 201001), pp. 0601 (2010).

12. Catapano, F., Sementa, P. and Vaglieco, B.M. "Optical characterization of bio-ethanol injection and combustion in a small DISI engine for two wheels vehicles", Fuel, 106, pp. 651-666 (2013).

13. Kourmatzis, A., Pham, P. and Masri, A. "Air assisted atomization and spray density characterization of ethanol and a range of biodiesels", Fuel, 108, pp. 758-770 (2013).

14. Padala, S., Le, M.K., Kook, S. and Hawkes, E.R. "Imaging diagnostics of ethanol port fuel injection sprays for automobile engine applications", Applied Thermal Engineering, 52(1), pp. 24-37 (2013).

15. Agarwal, A.K., Dhar, A., Gupta, J.G., Kim, W.I., Lee, C.S. and Park, S. "Effect of fuel injection pressure and 
injection timing on spray characteristics and particulate size-number distribution in a biodiesel fuelled common rail direct injection diesel engine", Applied Energy, 130, pp. 212-221 (2014).

16. Chen, R. and Nishida, K. "Spray evaporation of ethanol-gasoline-like blend and combustion of ethanolgasoline blend injected by hole-type nozzle for directinjection spark ignition engines", Fuel, 134, pp. 263$273(2014)$

17. Mohan, B., Yang, W. and Yu, W. "Effect of internal nozzle flow and thermo-physical properties on spray characteristics of methyl esters", Applied Energy, 129, pp. 123-134 (2014).

18. Kharazmi, S., Mozafari, A. and Hajilouy-Benisi, A. "Simulation and experimental investigation of performance and emissions of a turbocharged lean-burn natural gas engine considering thermal boundary layer", Scientia Iranica. Transaction B, Mechanical Engineering, 21(4), p. 1424 (2014).

19. Wang, F., He, Z., Liu, J. and Wang, Q. "Diesel nozzle geometries on spray characteristics with a spray model coupled with nozzle cavitating flow", International Journal of Automotive Technology, 16(4), pp. 539-549 (2015).

20. Martin, D., Pischke, P. and Kneer, R. "Investigation of the influence of multiple gasoline direct injections on macroscopic spray quantities at different boundary conditions by means of visualization techniques", International Journal of Engine Research, 11(6), pp. 439-454 (2010).

21. Liu, Y., Yeom, J. and Chung, S. "A study of spray development and combustion propagation processes of spark-ignited direct injection (SIDI) compressed natural gas (CNG)", Mathematical and Computer Modelling, 57(1), pp. 228-244 (2013).

22. Elkotb, M. "Fuel atomization for spray modelling", Progress in Energy and Combustion Science, 8(1), pp. 61-91 (1982).

23. Chikahisa, T., Yuyama, R., Kikuta, K. and Hishinuma, Y. "Entropy analysis of microscopic diffusion phenomena in diesel sprays", JSME International Journal. Series B, Fluids and Thermal Engineering, 46(1), pp. 109-116 (2003).

24. Lacoste, J., Characteristics of Diesel Sprays at High Temperatures and Pressures, University of Brighton (2006).

25. Gao, Y., Deng, J., Li, C., Dang, F., Liao, Z., Wu, Z. and Li, L. "Experimental study of the spray characteristics of biodiesel based on inedible oil", Biotechnology Advances, 27(5), pp. 616-624 (2009).

26. Soid, S. and Zainal, Z. "Spray and combustion characterization for internal combustion engines using optical measuring techniques-a review", Energy, 36(2), pp. 724-741 (2011).

27. Chitsaz, I., Saidi, M.H. and Mozafari, A.A. "Semi analytical solution to transient start of weakly underex- panded turbulent jet", Journal of Fluids Engineering, 133(9), pp. 091204 (2011).

28. Chitsaz, I., Saidi, M.H., Mozafari, A.A. and Hajialimohammadi, A. "Experimental and numerical investigation on the jet characteristics of spark ignition direct injection gaseous injector", Applied Energy, 105, pp. 8-16 (2013).

29. Kim, H.J., Park, S.H. and Lee, C.S. "Overall spray characteristics of dimethyl ether and biodiesel fuel under the ambient pressure conditions in a high pressure chamber", Journal of Thermal Science and Technology, 4(3), pp. 391-399 (2009).

30. Wang, X., Huang, Z., Kuti, O.A., Zhang, W. and Nishida, K. "Experimental and analytical study on biodiesel and diesel spray characteristics under ultrahigh injection pressure", International Journal of Heat and Fluid Flow, 31(4), pp. 659-666 (2010).

31. Ejim, C., Fleck, B. and Amirfazli, A. "Analytical study for atomization of biodiesels and their blends in a typical injector: surface tension and viscosity effects", Fuel, 86(10), pp. 1534-1544 (2007).

32. Mohammadi, M., Mohammadi, M., Ghahremani, A.R., Shafii, M.B. and Mohammadi, N. "Experimental investigation of thermal resistance of a ferrofluidic closed-loop pulsating heat pipe", Heat Transfer Engineering, 35(1), pp. 25-33 (2014).

33. Delacourt, E., Desmet, B. and Besson, B. "Characterisation of very high pressure diesel sprays using digital imaging techniques", Fuel, 84(7), pp. 859-867 (2005).

34. Naber, J.D. and Siebers, D.L. "Effects of gas density and vaporization on penetration and dispersion of diesel sprays", In SAE Technical Paper (1996).

35. Desantes, J., Payri, R., Salvador, F. and Gil, A. "Development and validation of a theoretical model for diesel spray penetration", Fuel, 85(7), pp. 910-917 (2006).

36. Zhang, W., Nishida, K., Gao, J. and Miura, D. "An experimental study on flat-wall-impinging spray of microhole nozzles under ultra-high injection pressures", Proceedings of the Institution of Mechanical Engineers, Part D: Journal of Automobile Engineering, 222(9), pp. 1731-1741 (2008).

37. Wu, Z., Zhu, Z. and Huang, Z. "An experimental study on the spray structure of oxygenated fuel using laserbased visualization and particle image velocimetry", Fuel, 85(10), pp. 1458-1464 (2006).

38. Reitz, R.D. "Atomization and other breakup regimes of a liquid jet", PhD Thesis, Princeton University (1978).

\section{Biographies}

Amir Reza Ghahremani is a $\mathrm{PhD}$ candidate in school of Mechanical Engineering in Sharif University of Technology, Tehran, Iran. He has been working with 
Professors M.H. Saidi and A.A. Mozafari, since 2008, in the area of heat transfer. His research interests include bio-fuel, combustion, heat transfer, visualization, and pulse tube refrigerator.

Mojtaba Jafari has an MSc degree from University of Tehran, Tehran, Iran. He has been working in the area of heat transfer, biofuel, and internal combustion engines.

Mohammad Ahari has an MSc degree from University of Tehran, Tehran, Iran. His research interests are internal combustion engines and bio-diesel fuel.

Mohammad Hassan Saidi is a Professor of Mechanical Engineering and Director of Center of Excellence in Energy Conversion (CEEC), Sharif University of Technology, Tehran, Iran. His current research inter- ests include heat transfer enhancement in boiling and condensation, combustion modeling and simulation, modeling of pulse refrigeration, vortex tube refrigerators, indoor air quality and clean room technology, and energy efficiency in home appliances and desiccant cooling systems.

Ahmad Hajinezhad is an Assistance Professor of Department of Renewable Energy and the Environment, University Tehran, Tehran, Iran. His current research interests include energy economics, bio-fuel, energy conversion, and environmental issues.

Ali Asghar Mozafari is a retired Professor of Mechanical Engineering, Sharif University of Technology, Tehran, Iran. His research interests include energy conversion, internal combustion engine, and power systems. 